\title{
Role of Vectors and Climate Change on the Epidemiology of Rift Valley Fever
}

Keywords: Rift valley fever, transmission, vectors, climate change. Abstract

Rift Valley fever (RVF) is an emerging viral zoonosis that causes frequent outbreaks in east Africa and on the Arabian Peninsula. It's caused by Rift Valley fever virus (RVFV) of genus phlebovirus, which is a high priority pathogen because of its economic and public health importance. It can cause miscarriage in pregnant animals and a high mortality in young animals and in human RVF causes a severe influenza like illness. The major outbreaks of the disease have been reported to occur throughout much of sub-Saharan Africa, Egypt, in the Middle East (Saudi Arabia and Yemen) and the island of Madagascar. Its occurrence is highly associated with the effect of the warm phase of the El Nino/Southern Oscillation (ENSO) phenomenon which resulted in abnormal heavy rainfall which in turn allow flooding of the vector's habitat. Transmission of RVF during the endemic cycles requires the involvement of Aedes mosquito species which serve as the primary maintenance vectors of the disease. Infected Aedes species transmit the virus transovarially to their eggs. The egg of these endemic vectors remains viable during dry period for long periods. Then, following period of abnormally heavy rainfall flooding of their habitat occurs and the eggs start to hatch and then generating infected mosquito species. These hatched mosquito species start to disseminate the virus to nearby animals followed by other biting mosquito (Culex and Anopheles) which in turn feed on the blood of viremic animals and contribute to the epidemic transmission of virus, serve as secondary amplifier of the virus. Immunization of animals, destruction of mosquitoes and restriction on the movement of animals during epizootic can help in the control of RVF. The likelihood of RVF global expansion is due to climate change and environmental modification is an important issue. Thus, great focus is needed to deal on the influence of climate change on the vector population and their effect on the occurrence of the disease.

\section{Introduction}

Rift Valley fever (RVF) is an arboviral zoonotic disease that is endemic in the African continent but has also spread to the Arabian Peninsula and Yemen, where it was first reported in the year 2000. It's caused by Rift Valley fever virus (RVFV) which is a high priority pathogen because of its potential for causing; severe economic impact (due to abortion and neonatal mortality), life-threatening hemorrhagic fever in humans, and its potential for non-vector aerosol spread during epizootics and epidemics. The disease pattern in the Eastern African region and the horn of Africa is driven by climatic conditions linked to the El Niño/Southern Oscillation (ENSO) phenomenon, which leads to unusual high rainfall and floods alternated by long dry spells. In other parts of Africa, RVF emerged in relation to the construction of hydroelectric power dams along Senegal river and thereafter established itself as endemic disease. In the Arabian Peninsula RVF was introduced through trading of live animals with countries in the horn of African [1-5].

In east Africa, RVF emergence is partly caused by the vertical transmission of the virus in eggs of Aedes species, especially those belonging to the Neomelaniconion subgenus, which breed in isolated depressions called dambos found in the vast grassland areas
Journal of

Veterinary Science \& Medicine

Begna Bulcha Guta ${ }^{1}$, Mehari Tarafa ${ }^{2}$, Samson leta Regassa $^{3^{*}}$

${ }^{123}$ Department of Biomedical Science, Addis Ababa University, college of veterinary medicine, Bishoftu, Ethiopia.

*Address for Correspondence

Samson Leta Regassa, Department of Biomedical Science, Ad dis Ababa University, college of veterinary medicine.Bishoftu, Ethiopia. Email: samiwude@gmail.com

Submission: 02 March, 2019

Accepted: 04 April, 2019

Published: 06 April, 2019

Copyright: ๑ 2019 Regassa SL, et al. This is an open access article distributed under the Creative Commons Attribution License, which permits unrestricted use, distribution, and reproduction in any medium, provided the original work is properly cited.

flooding of the dambos occurs during periods of extensive and widespread rainfall which resulted from climate changes usually El Niño following flooding of their habitat the eggs of the Aedes mosquitoes (primary/enzootic vectors) started to hatch and the subsequent adults transmit the virus to domestic animals including sheep, goats, cattle, and camels [6-8].

Flooding of these depressions also serve as good habitats for other mosquito species Culex and Anopheles (secondary/epizootic vectors). When Aedes mosquitoes infect domestic animals with RVFV, virus amplification occurs in these vertebrate hosts, leading to propagation into various Culex and Anopheles species that are capable of transmitting the virus to wide area beyond the area of original outbreak by wind borne dispersal thus, RVF occurrences are closely associated with periods of heavy rains, in Africa, due to the effect rainfall pattern on the hatching dynamic of mosquitoes. RVF causes significant losses in terms of human illnesses, livestock abortions and neonatal death. In ruminant livestock, especially sheep and cattle, the disease is characterized by high mortality rate that reach $10-20 \%$ in adult animals and up to $100 \%$ in neonatal animals. The disease is also associated with high abortion rates particularly in infected pregnant animals especially in sheep whereas it is manifested by blurred vision, retinal lesions, headache, lethargy, myalgia, fever, hemorrhages and loss of memory in humans [9-12]

In the countries where the disease is endemic, particularly in developing countries of tropical and sub-tropical areas, RVF causes a heavy economic impact. RVF epidemics causes' higher socioeconomic impact especially to populations those are totally dependent on livestock as source of income the negative impacts of the disease is not only affecting livestock producers, but also extended to various stakeholders in the marketing chain including livestock traders due to unsold animals during quarantine, slaughterhouses, casual laborers and butchers who were affected by imposition of slaughter bans during outbreaks. Furthermore, it seriously affects household nutrition due to loss of livestock and restriction of live animal movements, as well as, the ban imposed on slaughter houses climate changes affect the distribution and abundance of competent vectors of RVF by affecting their breeding environment which in turn worsens the frequency of occurrence and impacts of RVF across 
the continent. For this reason, more study is required to emphasize the synergistic effect of climate change and vectors in the occurrence of RVF. Therefore, the objective of this paper is; to overview the role of vectors, and to assess the impact of climatic change on the epidemiology of RVF [13-14].

\section{Overview of Rift Valley Fever}

RVF is an acute mosquito born viral disease mainly affecting ruminant animals and humans. It can cause abortion in pregnant animals and a high mortality in young animals in human RVF causes a sever influenza like illness, with occasionally more series hemorrhagic complications and death. Over its range, it causes major epidemics at irregular intervals of 5-15 years [11,15].

\section{Brief History of Rift Valley Fever}

RVF was first reported among livestock in Kenya in 1930, during an outbreak associated with high rates of miscarriage among pregnant ewes and acute deaths of newborn lambs on a sheep farm in the Rift Valley of Kenya Since then it has been reported as occurring not only in most African countries, but also in Arabian Peninsula, particularly in Saudi Arabia and Yemen. In 1950-1951, a major epizootic in Kenya caused 500,000 abortion and 100,000 deaths in sheep. Recently, RVF Outbreaks have been reported in Kenya in December 2006, following a period of heavier than usual rainfall and widespread flooding resulted in several hundred hemorrhagic fever cases with a significantly high mortality and this was recorded as the most devastating RVF outbreaks in east Africa, and then spread until December 2007 to Somalia. In Tanzania, major outbreaks were reported in Ngorongoro district in 1997-1998 and 2006-2007 causing massive abortions and deaths in livestock. The 2006-2007 outbreaks was reported in 25 districts following a heavy rainfall in Arusha, Manyara, Kilimanjaro, Tanga, Dodoma, Iringa, and Morogoro regions of the country causing 144 human deaths [16-19].

The most devastating RVF outbreaks were recorded in Egypt (outside sub-Sahara) in 1977 following the completion of Aswan dam, causing an estimated 598 human deaths as well as thousands of abortions in domestic animals subsequent outbreaks in Egypt occurred in 1993 was attributed to importation of infected ruminants specifically camels from Sudan in September 2000, outside the African continent RVF was first reported in Saudi Arabia and Yemen. This considers the first report of the disease occurrence outside the African continent where it had been confined so far becoming a threat to the Middle East. The spreads of the disease in Middle East (Saudi Arabia and Yemen) is resulted from improper quarantine measures during importation of infected animals from Eastern Africa as well as the extension of RVFV from Sudan to Egypt in 1977 [20-22].

In February 2010, as South Africa's National Institute of Communicable Diseases (NICD) reported to Center of Disease Control (CDC), an ongoing outbreak of Rift Valley Fever affecting both animals and humans occurred in seven provinces in South Africa. It was also reported that a total of 172 human cases of RVF and 15 deaths resulted. At the time it was indicated out of 172 data $81 \%$ of the patient had direct contact with animals through their work with RVF-infected ruminants. Starting in September, 2013 the outbreak of RVF reported in northern Saint Louis region of Senegal, in which the disease was detected in dorcas gazelle and domestic ruminants by Reverse Transcriptase polymerase chain reaction (RTPCR). From September 2013 to January 2014 large but unspecified number of ruminants, camels, and human cases were reported from five different areas in Mauritania. The more recent outbreak of RFV was reported in late August 2016 in Niger. As of December 2016, the World Health Organization (WHO) Niger country office reported a total of 384 human cases, with 33 deaths whereas no data available neither on morbidity nor mortality status in animals [23-25].

\section{Epidemiology of Rift Valley Fever}

Etiology and its Transmission: RVF is caused by RVFV which belongs to genus Phlebovirus of the family Bunyaviridae. Like other Bunyaviruses, the genome of the virus consists of three negative stranded RNA segments called the L (large), M (medium), and S (small) segments encoding four structural proteins, viral polymerase (L segment), glycoproteins ( $\mathrm{M}$ segment) and nucleocapsid protein $\mathrm{N}$ (S segment). The RVFV is resistant to alkaline environment but rapidly inactivated below $\mathrm{pH} 6.8$; the ideal $\mathrm{pH}$ range is $7-8$. The agent can survive for several months at $4^{\circ} \mathrm{C}, 21$ days at $37^{\circ} \mathrm{C}$ and 4 months at $25^{\circ} \mathrm{c}$. The RVFV is inactivated by ultraviolet radiation and strong sunlight; due to a lipid bilayer in the virion envelope, the virus is susceptible to lipid solvents e.g. sodium or calcium hypochlorite [2627].

The transmission of RVFV during inter-epidemic period involves vertical transmission among Aedes mosquito species infected with RVFV while feeding on viremic animals, so that the virus is transmitted to the nascent eggs transovarially. These mosquitos' species lay their eggs in pond mud. When ponds dry up, these eggs they remain viable for several years or even decades in the dry mud and allow the virus to persist in the field during dry and/or interepizootic periods for long periods of time [6]. Then an endemic transmission of the virus occurs following a period of heavy rainfall which results in a massive hatching episode of transovarially infected primary vectors and results in the development of both infected and uninfected vector populations. The infected ones if feeding on nearby vulnerable ruminants/livestock would then trigger virus amplification. Once RVFV has been amplified in livestock, other mosquito species of Culex and Anopheles genera spread the virus to other vertebrate hosts while they feed on blood of viremic and health animas transmission during epidemic cycle is driven by persistence of above normal rainfall which in turn raises the level of water and floods the grassland depressions sufficiently to produce stagnant water (dambos). Subsequently, it leads to elevation of various genera of Culex and Anopheles mosquito populations, which serve as excellent secondary vectors of RVF. These mosquito species become involved in the further transmission of the virus leading to occurrence of epidemic transmission of RVFV while they feed on the blood of infected animals. In addition to this, other biting flies such as Stomaxy spp. glossina spp. and tabanids which breed rapidly in stagnant water area and perpetuate dramatically the transmission of RVF mechanically to a large extent beyond the outbreak area [28-30].

From domestic animals, the virus is transmitted to humans mainly through direct contact with blood or percutaneous injury during slaughtering, necropsy of viraemic animals, contact with infected 


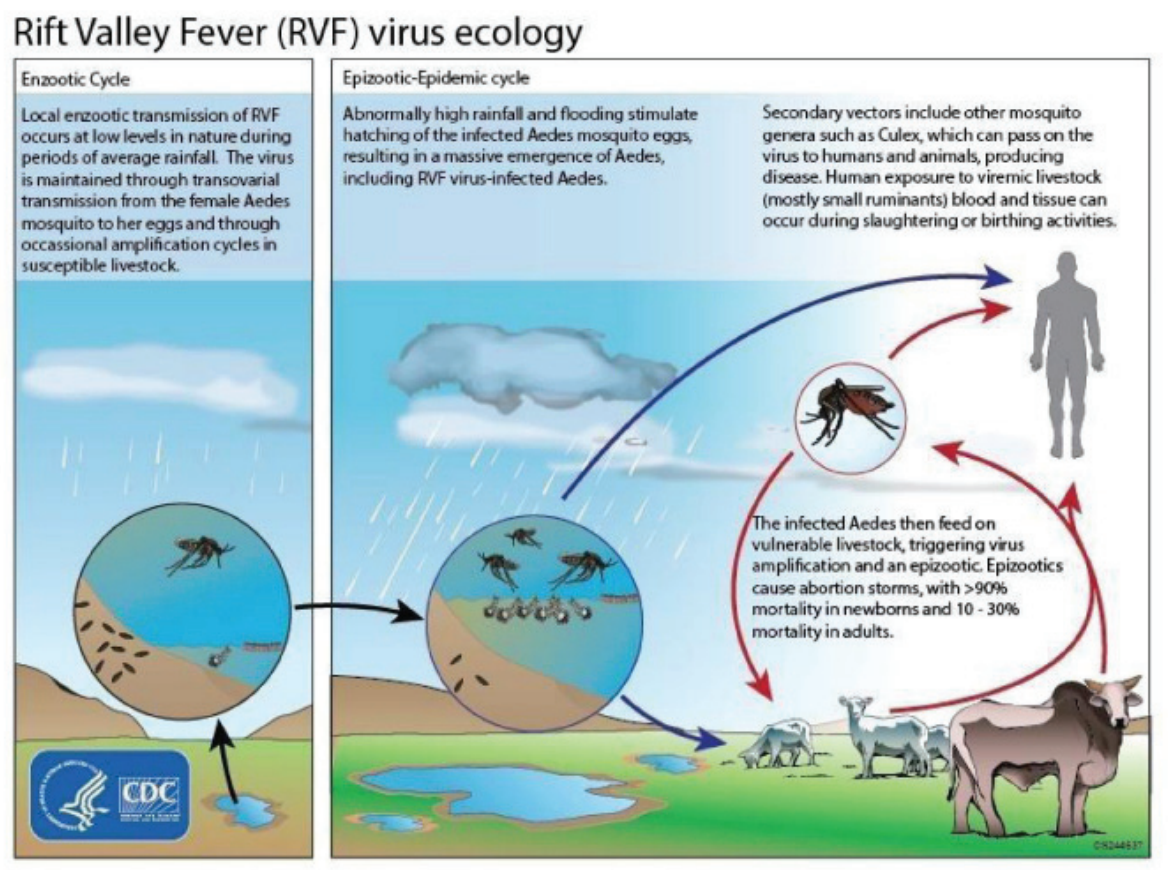

Figure 1: The Ecological Cycle of RVF virus.

placenta or aborted fetus, fomites or mechanical transport on the mouth part of flies, or secretions of infected animals, consumption of raw milk, and in few cases, transmission through mosquito bites that belong to the genera Anopheles, Aedes, and Culex seems to occur [9]. To elaborate this the ecology of RVF is depicted by (figure 1).

Distribution and Occurrence: RVF is regarded as endemic to large parts of sub-Saharan Africa, but it has also been recorded outside the sub-Saharan Africa in Egypt and Madagascar, outside the African continent in the Middle East (Saudi Arabia and Yemen). This shows the potential of the disease to spread to other parts of the world as tried to illustrated by geographical distribution map the RVF has also the potential for global spread, due to the contribution of different factors such as wide distribution of competent vectors, ecological tolerance of the RVFV, the intense viraema associated with infection and an extension of suitable habitat as a result of environmental change can influence the rapid range expansion of the disease. Despite the extensive suitability ranges for Ae. aegypti (the potential vector of RVF) in the Americas, Pacific Ocean, and Southeast Asian countries, no reports of RVF have been made from these regions [31-34]. (Figure 2)

The occurrence of RVF can be endemic and/or epidemic, depending on the climatic and ecological characteristics of different geographic regions. The disease was shown to be endemic in some semi-arid zones, such as northern Senegal. Epidemic areas are characterized by plateau grasslands with relatively high rainfall (East Africa), semi-arid zones (Saudi Arabia, West Africa), irrigated zones (Egypt, Yemen). In these areas, RVF epidemics appear at 5 to 15 year cycles and the generation of epidemics seems to be associated with the simultaneous intensification of virus activities over vast livestock areas, where it is already present as cryptic endemic foci [7].

\section{Role of Vector and Climate Change in the Occurrence of Rift Valley Fever}

Vectors of Rift Valley Fever: RVF is usually transmitted to mammals by mosquitoes and it is transmission rate usually depends on the availability of competent vectors, hosts, and appropriate ecological and environmental conditions which influences mosquito survival and reproduction. These vectors are classified into two major groups, namely primary and secondary vectors [35].

Primary vectors: Primary vectors are those vectors belong to genus Aedes which acts as reservoir vector, and they are generally thought to be responsible for maintaining the disease through the inter-epizootic period in endemic areas, through vertical transmission from adult to egg. These primary vectors include Ae. mcinthoshi, Ae. ochraceus, Ae. dalzieli, Ae. aegypti and Ae. vexans and they usually serve as maintenance vectors and initiate transmission of RVFV to amplifying hosts leading to initiation of outbreaks in RVF endemic areas this mosquito species are numerous and they change depending on the ecosystems involved [36].

Secondary vectors: Secondary vectors particularly genus Culex acts as the amplifying vector and members of this genus have ubiquitous biting patterns and develop disseminated infections by ingesting blood meals from viremic livestock and are responsible for the rapid spread of RVFV during outbreaks these secondary vectors include mosquitoes of many species of the genera Anopheles ( $A n$. squamosus, An. coustani), Culex (Cx. pipiens and $C x$ poicilipes), Eretmapodites (Er. quinquevittatus), and Mansonia (Ma. uniformis and Ma. africana). They take over flooded ground for breeding, contribute for the amplification of virus and disseminate infections resulting in the occurrence of outbreaks $[37,38]$. 


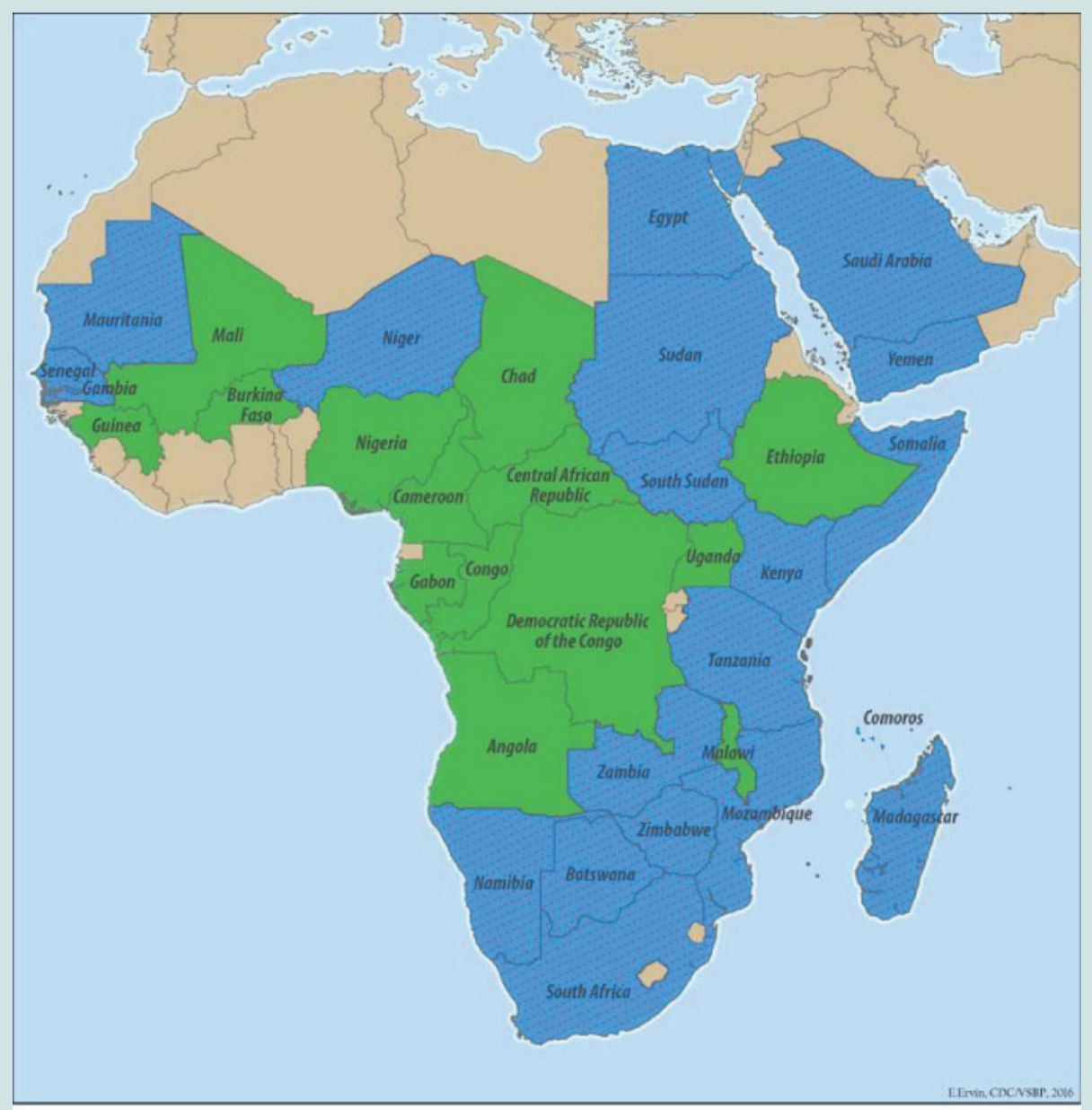

\section{Rift Valley Fever Distribution Map}
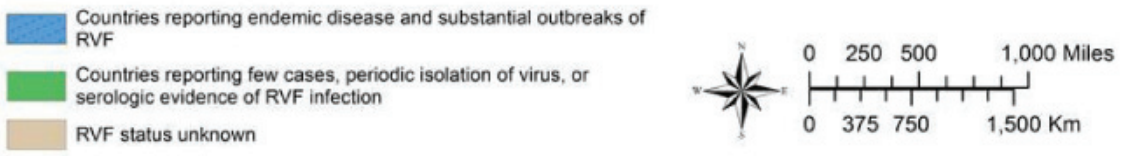

Figure 2: Rift Valley distribution maps.

Climate Change and Vectors: Global climate change will induce changes in the magnitude and frequency of extreme events and have significant effects on the geographical range and seasonal activity of many vector species. It is therefore expected that global climate change will alter the distribution and increase the risk of RVF, leading to significant changes in the geographical distribution and frequency of RVF epidemics [7]. In addition, Global temperature change would affect the biology of vectors including feeding rate, egg production, the length of the development cycle and the extrinsic incubation period. This may result in high vector density, an increased vector capacity to transmit the virus and results in a high transmission rate of the disease. Sustained climate shifts will therefore lead to changes in the RVF burden in endemic areas and new outbreaks in areas of similar conditions [39].

\section{Heavy rainfall and flooding}

Periodic widespread and heavy rainfall leads to extensive and widespread flooding of mosquito habitats. These heavy and persistent rainfalls are known to occur during the warm phase of the ENSO phenomenon. El Niño is a complex and naturally occurring weather pattern that results when ocean temperatures in the Pacific Ocean near the equator vary from the normal this phenomenon typically occurs every two to seven years causing abnormally heavy rains and storms and can last for about 9-12 months.. This abnormally heavy rainfall allow the periodic occurrence of RVF as it creates suitable breeding site for mosquito and pushing epidemics to occur every 5-15 years in East Africa. The El Niño-Southern Oscillation (ENSO) is the main driver of the interannual variability in eastern African rainfall, with significant impact agriculture and dire consequences for food and social security. There has been a lot research investigating the effects of El Niño and La Niña on climate (temperature, rainfall, 
snowpack, climate extremes,) around the world and this has indirect effect prevalence of vector borne disease like RVF by creating conducive condition for vector population. However, these impacts can be different from year-to-year due to the varying nature of ENSO, and variations in the atmosphere-ocean system. This natural phenomena definitely impacts upon the distribution, and lifecycle, of insects. An excellent example is the impact of ENSO on the increased incidence of Rift Valley Fever (RVF). This is due to the fact that the genus Aedes, responsible for transmitting RVF, performs well during periods of flooding. The El Niño lead to dramatic change in the thermal east-west gradient of the Pacific ocean surface temperatures which in turn results in the displacement and shifts in the normal zonal atmosphere ocean circulation patterns in the global tropics. Sometimes the effects of these atmospheric circulation shifts extend into the subtropical Northern Hemisphere. These changes in the tropical ocean atmosphere moisture energetic lead to anomalous climatic conditions, in particular dramatic shifts in precipitation patterns. For this reason, Regions that are typically dry, receive above normal rainfall, and those that are typically wet, experience drought conditions during El Niño. In Africa, the most dramatic manifestation of these shifts in rainfall patterns is manifested by above normal rainfall over a large area of equatorial Eastern African, particularly semi arid areas of Kenya, Somalia, and Ethiopia and droughts over a large area of Southern Africa. The rainfall over East Africa at times persists for several months, as was observed during the 1997-1998 ENSO warm event, and results in extensive flooding over most the Africa. Consequently, RVFV epizootics occur when these ENSO-related periods of heavy rainfall flood natural landscape depressions, then breeding of transovarially infected eggs of Aedes mosquito species occur. Due to the persistence of RVFV in transovarially infected floodwater Aedes species, epizootic outbreaks are initiated as this mosquito species are hatched during periods of heavy rainfall. Also, increased precipitation associated with rainfalls causes an increase in the availability of breeding grounds for the disease carrying mosquitoes [40-45].

In addition to flooding, modification of the environment has been associated with outbreaks of diseases transmitted by mosquitoes and in the case of RVF this is reflected in the building of dams. Because the dam had created many hectares of flood lands and increased the breeding ground of mosquitoes, adding impetus to the outbreak. For example, 1977 in Egypt following the completion of the Aswan dam, more than 200,000 people became sick, 598 deaths occurred and livestock losses resulted in meat shortages. A second dam linked incident occurred in 1987 in West Africa. One year after the construction of the Diama dam along the Senegal River, an outbreak of RVF was recorded in northern Senegal and Mauritania. During this period clinical evidence of the disease have been recorded in livestock leads to Abortion losses and thousands of people became sick and about one fifth of those died [46].

\section{Risk of Rift Valley Fever in Ethiopia}

In Ethiopia no clinical cases have been reported. However, occurrence of the disease has been reported to World Organization for Animal Health (OIE) in 2006 although clinical evidence of the disease have never been reported in Ethiopia, its geographical proximity to RVF endemic countries like Kenya, Sudan and Somalia, the nature of livestock movements across the international border and the ease with which infected mosquitoes can be moved longer distances by the help of wind will lead to the conclusion that Ethiopia will always be vulnerable to clinical RVF during the epizootic periods of the disease in East Africa [47].

Furthermore, if single or small number of infected vector or host animals is introduced successfully into RVF free areas, transmission of the virus to local animal hosts and competent domestic vectors can facilitate spread of the virus. In addition to this, in Ethiopia increased dam construction and irrigation activity supposed to make suitable breeding sites for RVF vectors and make the country vulnerable to the disease following epidemics of RVF in Kenya and Somalia in 1997/98, import of livestock and their products was banned by the Gulf Arab countries; from nine countries of the Horn of Africa Ethiopia was one of them with no identified problem of the disease but victimized for its proximity to the countries with the problem and for it has no any scientific evidence proving the nonexistence of the disease. The annual export loss for Ethiopia due to the ban was more than 18 million [48].

\section{Control and Prevention of Rift Valley Fever}

Environmental Measures: The incidence of RVF can be reduced by restricting the animals to mosquito proof sheds and by movement of livestock from low lying areas to well drain and winds wept pastures of higher altitude. Also preventing lambing or calving during the rainy season is the best management to reduce exposure of neonates to biting Aedes [49].

Vector Control: Vector control programs can be implemented at different stages of mosquitos' development. Adult mosquitoes can be controlled by focusing on the use of pesticides. It can be implemented by targeting resting adults through barrier spraying of vegetation or artificial substrates or by directly targeting flying or resting adults with either thermal fogging or ultra-low volume (ULV) spraying [50].

New approach like, One Health is an integrated approach for the understanding and management of animal, human, and environmental determinants of complex problems such as RVF. By applying consistent One Health approach, it possible to provoke the participation of local communities in surveillance and control of RVF efforts, rather than continuing their current status as passive victims of the periodic RVF incursions [51].

Vaccination: Like other viral diseases, the prevention of RVF relies heavily on vaccination of all susceptible animals to prevent infection of amplifying hosts by granting long term protective immunity and preventing infection of vectors two types of vaccines have been developed for immunization against RVF: live attenuated vaccines (Smithburn vaccine) and inactivated vaccines (formalin inactivated) [52-54].

\section{Conclusions and Recommendations}

Rift valley fever is mosquito borne viral disease of ruminants and humans. This review explained that the disease causes storms of abortion and neonatal ruminant mortality with subsequent zoonosis and hemorrhagic fever which can generate a sense of panic in the public. Previously the disease is restricted to specific areas in sub- 
Saharan Africa; however, the disease is currently spreading into new territories beyond the traditional foci as evidenced by outbreaks in the Arabian Peninsula. Increased vector populations, ecological factors and climatic changes are determinant epidemiology and risk of disease outbreaks in rift valley belt of Africa. Generally, it is reviewed that multiple factors shapes the epidemiology of RVF, among these are rainfall and flooding which alters vector populations by creating a suitable breeding sites for mosquitoes. Thus, it is recommended that; governments should state clear strategies and action plans for emergency preparedness to handle future outbreaks of RVF, integrated vector control measures should be practiced under different vector control units in the respective ministries, control of animal movement and biosecurity measures should be placed especially for countries free of the disease, and as dam construction and irrigation activity recently started in Ethiopia may produce conducive condition for vector populations, awareness and implementation of strategic prevention methods needs to considered.

\section{References}

1. Ondiba IM, Oyieke FA, Nyamongo IK, Estambale BA. (2017) Diversity, Distribution and Abundance of Potential Rift Valley Fever Vectors in BaringoCounty, Kenya. Int J Mosq R. 4: 42-48.

2. Isaacson M (2001) Viral Hemorrhagic Fever Hazards for Travelers in Africa. Clin Infec Dis. 33: 1707-1712.

3. Anyamba A, Chretien JP, Small J, Tucker CJ. Formenty PB et al. (2009) Prediction of a Rift Valley Fever Outbreak. Pro Nati Acad Sci U S A. 106: 955-959.

4. Chevalier V, Thiongane $Y$, Lancelot R (2009) Endemic transmission of Rift Valley Fever in Senegal. Transbound Emerg Dis. 56: 372-374.

5. Soumare B, Tempia S, Cagnolati V, Mohamoud A, Van Huylenbroeck G (2007) Screening for Rift Valley Fever Infection in Northern Somalia: A GIS Based Survey Method to Overcome the Lack of Sampling Frame. Vet Microbiol. 121: 249-256.

6. Tantely LM, Boyer S, Fontenille D (2015) A Review of Mosquitoes Associated with Rift Valley Fever Virus in Madagascar. Am J Trop Med Hyg. 92: 722-729.

7. Martin V, Chevalier V, Ceccato P, Anyamba A, De Simone L, Lubroth $\mathrm{J}$, de La Rocque S. et al (2008): The Impact of Climate Change on the Epidemiology and Control of Rift Valley Fever. Sci Tech Rev. 27: 413-426.

8. Mondet B, Diaite A, Ndione JA, Fall AG, Chevalier V. et al (2005) Rainfall Patterns and Population Dynamics of Aedes (Aedimorphus) vexan arabiensis, Patton 1905 (Diptera: Culicidae), a Potential Vector of Rift Valley Fever Virus in Senegal. J Vector Ecol. 30: 102-106.

9. Seufi AM, Galal FH. (2010) Role of Culex and Anopheles Mosquito Species as Potential Vectors of Rift Valley Fever Virus in Sudan Outbreak, 2007. BMC Infect Dis. 10: 65.

10. Anyamba A, Linthicum KJ, Small JL, Collins KM, Tucker CJ. (2012) Climate Teleconnections and Recent Patterns of Human and Animal Disease Outbreaks. PLoS Negl Trop Dis. 6: e1465

11. Sindato C, Karimuribo E, Mboera LE (2011) The epidemiology and socioeconomic impact of rift valley fever epidemics in Tanzania: a review. Tanzan J Health Res. 13: 305-318.

12. Mansfield KL, Banyarda AC, Mc Elhinneya L, Johnsona N, Hortonc DL, et al (2015) Rift Valley fever virus: A review of diagnosis and vaccination, and implications for emergence in Europe, Vaccine 33: 5520-5531.

13. Pachka H, Annelise T, Alan K, Power T, Patrick K, Véronique $C$, Janusz P. et al (2016): Rift Valley Fever Vector Diversity and Impact of Meteorological and Environmental Factors on Culex pipiens Dynamics in the Okavango Delta, Botswana. Parasit Vectors 9: 434.

14. Rich KM, Wanyoike F (2010) An Assessment of the Regional and
National Socioeconomic Impacts of the 2007 Rift Valley Fever Outbreak in Kenya. Am J Trop Medl Hyg. 83: 52-57.

15. FAO (2000) Rift valley fever threatens livelihood in horn of Africa: Empress Trans- boundary animal disease Bulletin Number 15.

16. Paweska JT. (2015) Rift Valley Fever. Rev sci tech. 34: 375-389.

17. Madani TA, Al-Mazrou YY, Al-Jeffri MH, Mishkhas AA, Al-Rabeah AM, et al (2003) Rift Valley Fever Epidemic in Saudi Arabia: Epidemiological, Clinical, and Laboratory Characteristics. Clin Infec Dis. 37: 1084-1092.

18. Davies FG. (2010) The Historical and Recent Impact of Rift Valley Fever in Africa. Am J Trop Med Hyg. 83: 73-74.

19. Chengula AA, Mdegela RH, Kasanga CJ (2013) Socio-Economic Impact of Rift Valley Fever to Pastoralists and Agro Pastoralists in Arusha, Manyara And Morogoro Regions in Tanzania. Springerplus, 2: 549.

20. Abd el-Rahim IH, Abd el-Hakim U, Hussein M (1999) An Epizootic of Rift Valley Fever in Egypt in 1997. Rev sci tech.18: 741-748.

21. Gerdes GH. (2004: Rift Valley Fever. Rev sci tech. 23: 613-623.

22. Sayed-Ahmed M., Nomier Y. and Shoeib S. M. (2015): Epidemic Situation of Rift Valley Fever in Egypt and Saudi Arabia. J Dairy Vet Anim Res. 2: PP. 1-3.

23. WHO Disease Outbreak News (2010): Rift Valley Fever in South Africa.

24. Sow Abdourahmane, Ousmane Faye, Yamar Ba, Hampathé Ba, Diawo Diallo, et al ( 2016) Widespread RVF emergence in Senegal, 2013- 2014 External, Open Forum Infect Dis. 3: ofw149.

25. FAO (2017) RIFT VALLEY FEVER IN NIGER, Risk assessment. pp, 1-12.

26. Won S, Ikegami T, Peters CJ, Makino S (2006) Nsm and 78-Kilodalton Proteins of Rift Valley Fever Virus are Nonessential for Viral Replication in Cell Culture. J Virol. 80: 8274-8278.

27. Swanepoel R, Coetzer JAW (2004): Rift Valley Fever: Infectious diseases of livestock, Coetzer JAW. Tustin RC (eds) Cape Town: Oxford University Press Southern Afr. 2: 1037-1070. pp: 1-14.

28. Pepin M, Bouloy M, Bird BH, Kemp A, Paweska J (2010) Rift Valley fever virus (Bunyaviridae: Phlebovirus), an Update on Pathogenesis, Molecular Epidemiology, Vectors, Diagnostics and Prevention. Vet Res. 41: 61.

29. Pedro SA, Abelman S, Tonnang HEZ (2016): Predicting Rift Valley Fever Inter epidemic Activities and Outbreak Patterns: Insights from a Stochastic Host-Vector Model. PLoS Negl Trop Dis. 10: e0005167.

30. Davies FG, Martin V (2003) Recognizing Rift Valley Fever. Food and agricultural organization of the United Nations. pp: 1-45.

31. Weaver SC, Reisen WK. (2010): Present and Future Arboviral Threats. Antiviral Res. 85: 328-345.

32. OIE (2004) Manual of Diagnostic Tests and Vaccines for Terrestrial Animals. Int Office Epizootics Publication Paris, France. pp: 1-634

33. Radostitis OM, Blood DC, Gay CC (2007) Veterinary Mericine, Text Book of the Disease of Cattle, Sheep, Pig, Goats and Horse.10 ${ }^{\text {th }}$ edition. Can Vet J. $51: 541$.

34. Leta S, Beyenea TJ, De Clercqb EM, Amenua K, Kraemerc MUG, Revie CW (2018) Global Risk Mapping for Major Diseases Transmitted by Aedes aegypti and Aedes albopictus. Int J Infect Dis. 67: 25-35.

35. Arum SO, Weldon CW, Orindi B, Landmann T, Tchouassi DP. et al (2015) Distribution and Diversity of the Vectors of Rift Valley Fever along the Livestock Movement Routes in the Northeastern and Coastal Regions of Kenya. Parasit Vectors. 8: 294.

36. Balenghien T, Cardinale E, Chevalier V, Elissa N, Failloux AB, Nipomichene TN (2013) Towards a better understanding of Rift Valley Fever Epidemiology in the South West of the Indian Ocean. Vet Res. 44: 78.

37. Biteye B, Fall AG, Ciss M, Seck MT, Apolloni A, Fall M, Tran A. et al (2018): Ecological Distribution and Population Dynamics of Rift Valley Fever Virus Mosquito Vectors (Diptera, Culicidae) in Senegal. 
Citation: Regassa SL, Guta BB, Mehari Tarafa. Role of Vectors and Climate Change on the Epidemiology of Rift Valley Fever. J Veter Sci Med. 2019;7(1): 7.

\section{SSN: 2325-4645}

38. Taylor D, Hagenlocher M, Jones AE, Kienberger S, Leedale J, Morse AP (2016) Environmental Change and Rift Valley Fever in Eastern Africa: Projecting Beyond Healthy Futures. Geospat Health. 11:387.

39. 39. Mpeshe SC, Luboobi LS, Nkansah-Gyekye Y (2014) Modeling the Impact of Climate Change on the Dynamics of Rift Valley Fever. Comput Math Methods Med. 2014: 627586.

40. Bett B, Kiunga P, Gachohi J., Sindato C, Mbotha D, Robinson T. et al (2016) Effects of Climate Change on the Occurrence and Distribution of Livestock Diseases. Prev Vet Med. 137: 119-129.

41. EMPRES (2015) EI Niño and increased Risk of Rift Valley Fever-Warning to Countries. Trans bound Anim Dis. 34: 1-8.

42. Anyamba A, Linthicum KJ, Tucker CJ (2001) Climate-Disease connections: Rift Valley Fever in Kenya. Cad Saude Publica. 17: 133-140.

43. Labeaud AD (2009) New Understanding of the Epidemiology of Rift Valley Fever Virus in Kenya. MSC thesis, Case West Reserve Univer. pp: 1-113.

44. Gerdes GH (2004) Rift Valley Fever. Rev Sci Tech. 23: 613-623.

45. OIE. (2006) World Animal Health Information Database (WAHIS) Interface Version 1.

46. Kasye M, Teshome D, Abiye A, Eshetu A (2016) A Review on Rift Valley Fever on Animal, Human Health and its Impact on Live Stock Marketing. Austin Virol Retrovirol. 3: 1020

47. Rolin Al, Berrang-Ford L, Kulkarni MA (2013) The Risk of Rift Valley Fever
Virus Introduction and Establishment in the United States and European Union. Emerg Microbes Infect. 2: 81.

48. Balcha M (2004) Retrospective and cross-sectional investigation of Rift Valley Fever in Small Ruminants in pastoral areas of Ethiopia. DVM thesis, Addis Ababa University, Bishoftu, Ethiopia.Faculty Vet Med.

49. Seifert, Horst SH (1996) Tropical animal. $2^{\text {nd }}$ Edition. Netherland: Kluwer Academic Publishers.

50. Bird BH, Nichol ST (2012) Breaking the Chain: Rift Valley Fever Virus Control via Livestock Vaccination. Curr opin virol. 2: 315-323.

51. Ikegami T, Makino S (2009) Rift Valley Fever Vaccines. Vaccine. 27: 69-72

52. Istem Fer, Britta Tietjen, Florian Jeltsch, and Christian Wolff,(2017): The influence of El Niño-Southern Oscillation regimes on eastern African vegetation and its future implications under the RCP8.5 warming scenario, Biogeosci. 14: 4355-4374.

53. El Vilaly AE, Arora M, Butterworth MK, El Vilaly MA, et al (2013) Climate, environment and disease: The case of Rift valley fever. Progress in Physical Geography. 37: 259-269.

54. Mohamed Fawzy, Yosa A. Helmy (2019) The One Health Approach is Necessary for the Control of Rift Valley Fever Infections in Egypt: A Comprehensive Review, Viruses. 11: 139. 